\title{
Efficient and Selective Photocatalytic Oxidation of Benzylic Alcohols with Hybrid Organic-Inorganic Perovskite Materials
}

Haowei Huang, ${ }^{\dagger}$ Haifeng Yuan, ${ }^{*}+\odot$ Kris P. F. Janssen, ${ }^{\ddagger}$ Guillermo Solís-Fernández, ${ }^{\ddagger}$ Ying Wang, $^{\S}$ Collin Y. X. Tan, ${ }^{\dagger}$ Dries Jonckheere, ${ }^{\dagger \odot}$ Elke Debroye, ${ }^{\ddagger}$ Jinlin Long, ${ }^{\S \odot}$ Jelle Hendrix, ${ }^{\ddagger \odot}$ Johan Hofkens, ${ }^{*}{ }^{\ddagger}$ Julian A. Steele, ${ }^{\dagger}$ and Maarten B. J. Roeffaers ${ }^{*},{ }^{\dagger}$

${ }^{\dagger}$ Department of Microbial and Molecular Systems, Centre for Surface Chemistry and Catalysis (COK), KU Leuven, Celestijnenlaan 200F, 3001 Leuven, Belgium

${ }^{\ddagger}$ Department of Chemistry, Faculty of Sciences, KU Leuven, Celestijnenlaan 200F, 3001 Heverlee, Belgium

${ }^{\S}$ State Key Laboratory of Photocatalysis on Energy and Environment, Fuzhou University, Fuzhou 350002, Fujian, PR China

\section{Supporting Information}

\begin{abstract}
The impressive optoelectronic performance and low production cost of metal halide perovskites have inspired applications well beyond efficient solar cells. Herein, we widen the materials engineering options available for the efficient and selective photocatalytic oxidation of benzylic alcohols, an industrially significant reaction, using formamidinium lead bromide $\left(\mathrm{FAPbBr}_{3}\right)$ and other perovskite-based materials. The best performance was obtained using a $\mathrm{FAPbBr}_{3} / \mathrm{TiO}_{2}$ hybrid photocatalyst under simulated solar illumination. Detailed optical studies reveal the synergetic photophysical pathways arising in $\mathrm{FAPbBr}_{3} /$ $\mathrm{TiO}_{2}$ composites. An experimentally supported model rationalizing the large conversion enhancement over the pure constituents shows that this strategy offers new prospects for metal halide perovskites in photocatalytic applications.
\end{abstract}

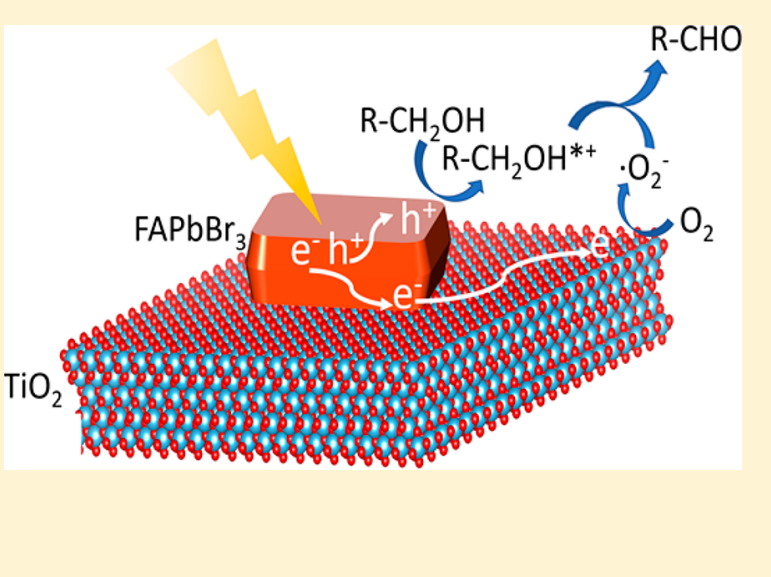

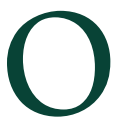
rganic-inorganic halide perovskites (OIHPs) have emerged as an extremely exciting family of semiconductor materials, garnering strong promise for a range of photonic applications. This stems from several advantages of OIHPs over other well-established semiconductors, such as low-cost facile processing, tunable band gaps, and superior charge transport properties. ${ }^{1}$ Early interest in OIHPs was sparked by their immediate success in efficient light harvesting. ${ }^{2,3}$ In just a few years, perovskite-based solar cell devices have rocketed to remarkably high power conversion efficiencies, exceeding 22\%. ${ }^{4}$

While novel photon-electrical and electrical-photon energy conversions using OIHPs continue to embody mainstream perovskites research, their application in photocatalytical and photoelectrochemical processes remains relatively unexplored. Among many candidates for semiconductor photocatalysts, titanium dioxide $\left(\mathrm{TiO}_{2}\right)$ is at present a prominent choice within both industry and fundamental research because of its wide optical band gap $(380 \mathrm{~nm})$, efficient photoactivity however limited to UV, high stability, and low cost. ${ }^{5}$ On the other hand, OIHPs offer strong potential to extend the efficient harvesting and utilization of light well into visible wavelengths. However, the inherent instability of organic halide perovskites when exposed to moisture makes them generally incompatible with typical photocatalytic reactions in aqueous media, like water splitting, $\mathrm{CO}_{2}$ reduction, and organic waste decomposition. Recently, Nam et al. ${ }^{6}$ overcame this limitation by using an oversaturated aqueous $\mathrm{HI}$ solution, and all-inorganic $\mathrm{CsPbBr}$ and $\mathrm{CsPbI}_{3}$ quantum $\operatorname{dots}^{7,8}$ have been applied in the photocatalytic reduction of $\mathrm{CO}_{2}$ and the oxidation of PEDOT, respectively. Considering how the interesting properties of OIHPs (high solar absorption and good charge separation and transport) continue to offer inexpensive solutions to a wide variety of optics research problems, it is surprising that serious efforts to exploit OIHPs for improving important photocatalytic reactions are yet to be made. One of the extremely important industrial organic reactions is the selective oxidation of alcohols to carbonyls, ${ }^{9,10}$ which is conventionally performed by stoichiometric quantities of

Received: January 26, 2018

Accepted: February 26, 2018

Published: February 26, 2018 
inorganic oxidant, notably dichromate and permanganate; noble metal catalysts $\mathrm{Pt}, \mathrm{Pd}$, and $\mathrm{Au}$; or organic oxidants such as 2,2,6,6-tetramethylpiperidine oxide. ${ }^{10-17}$

Herein we build on the strong photoactivity of formamidinium $\left(\mathrm{FA} ; \mathrm{HC}\left(\mathrm{NH}_{2}\right)^{2+}\right)$ lead bromide $\left(\mathrm{FAPbBr}_{3}\right)$ perovskites for the highly efficient and selective photocatalytic oxidation of benzylic alcohols. By utilizing the relative band alignment of photogenerated charge carriers within in $\mathrm{FAPbBr}_{3} / \mathrm{TiO}_{2}$ hybrids, ${ }^{18,19}$ the best performance under simulated solar illuminated was obtained. The photophysical pathways of photoexcited carriers within the hybrid system are detailed and are found to benefit from truly synergetic effects, namely, the improved separation and transport of electrons and holes into their respective active regions.

Our $\mathrm{FAPbBr}_{3}, \mathrm{TiO}_{2}$, and $\mathrm{FAPbBr}_{3} / \mathrm{TiO}_{2}$ samples are prepared using a simple room-temperature antisolvent precipitation method, ${ }^{20}$ with further procedural details provided in the Supporting Information. Pure $\mathrm{FAPbBr}_{3}$ and $\mathrm{TiO}_{2}$ crystallize into their thermodynamically stable cubic perovskite and anatase phases, respectively (powder X-ray diffraction (p-XRD), Figure S1). ${ }^{20-22} \mathrm{p}$-XRD of $\mathrm{FAPbBr}_{3} / \mathrm{TiO}_{2}$ consists of peaks from both phases, indicating successful synthesis of a $\mathrm{FAPbBr}_{3} / \mathrm{TiO}_{2}$ hybrid. Scanning electron microscopy (SEM) of the system further confirms this result, as shown in Figure S2. From the SEM micrographs, the average size of the pure $\mathrm{FAPbBr}_{3}$ is around $3 \mu \mathrm{m}$. In contrast, the average size of the hybrid material obtained via the same antisolvent precipitation, however in the presence of the anatase $\mathrm{TiO}_{2}$ as seed, is about $180 \mathrm{~nm}$, being 1 order of magnitude smaller than pure $\mathrm{FAPbBr}_{3}$. Besides their morphological differences, X-ray photoelectron spectroscopy (XPS) experiments (Figure S3) reveal no difference in the chemical state of the $\mathrm{FAPbBr}_{3}$ in the pristine or $\mathrm{TiO}_{2}$ mixed material. Rather, $\mathrm{TiO}_{2}$ influences the $\mathrm{FAPbBr}_{3}$ crystallization process yielding smaller crystals.

The optical absorption edges of $\mathrm{FAPbBr}_{3}, \mathrm{TiO}_{2}$, and $\mathrm{FAPbBr}_{3} / \mathrm{TiO}_{2}$ are determined from $\mathrm{UV}$-vis diffuse reflection spectroscopy (DRS, Figure 1). Typical band gaps are seen here for both pure materials: $380 \mathrm{~nm}(3.2 \mathrm{eV})$ for anatase $\mathrm{TiO}_{2}$ and $580 \mathrm{~nm}(2.2 \mathrm{eV})$ for $\mathrm{FAPbBr}_{3} .{ }^{21,23,24}$ Compared to bare $\mathrm{TiO}_{2}$, the absorption properties of $15 \% \mathrm{FAPbBr}_{3} / \mathrm{TiO}_{2}$ is enhanced substantially in the visible, through the superposition of both characteristic absorption spectra. The absorption edge corre-

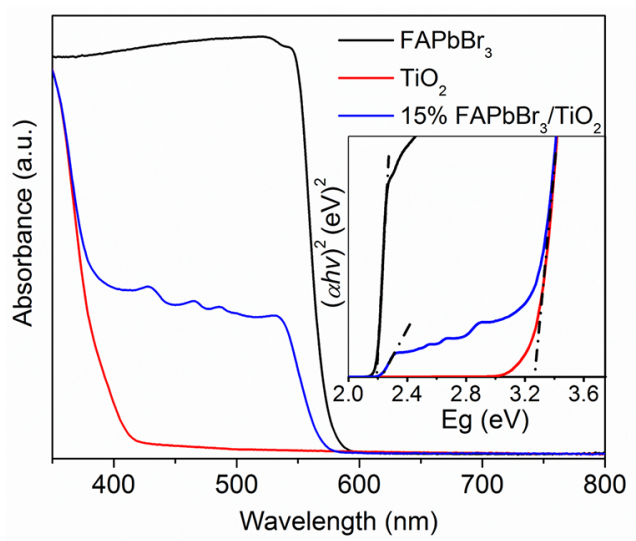

Figure 1. UV-Vis DRS spectra of $\mathrm{FAPbBr}_{3}, \mathrm{TiO}_{2}$, and $15 \%$ $\mathrm{FAPbBr}_{3} / \mathrm{TiO}_{2}$ with the corresponding band gaps shown in the inset. sponding to $\mathrm{FAPbBr}_{3}$ in the mixed material is slightly blueshifted by $10 \mathrm{~nm}$, relative to pure $\mathrm{FAPbBr}_{3}$, attributed to the reduced crystal sizes. ${ }^{24} \mathrm{FAPbBr}_{3} / \mathrm{TiO}_{2}$ materials with relative compositions of $1,5,10,20$, and 25 wt $\% \mathrm{FAPbBr}_{3}$ are also synthesized, with their optical properties summarized in Figure S4. In accordance with increasing absorption volume, elevating the relative concentration of $\mathrm{FAPbBr}_{3}$ in the composite also sees the weight of the Vis absorption increase.

Next, the photocatalytic properties of the full range of materials synthesized are evaluated under simulated solar illumination by applying the selective photocatalytic oxidation of benzylic alcohol in an apolar solvent (toluene) and using molecular oxygen. Their photocatalytic performances are displayed in Figure 2A, where the pure $\mathrm{FAPbBr}_{3}$ and $\mathrm{TiO}_{2}$

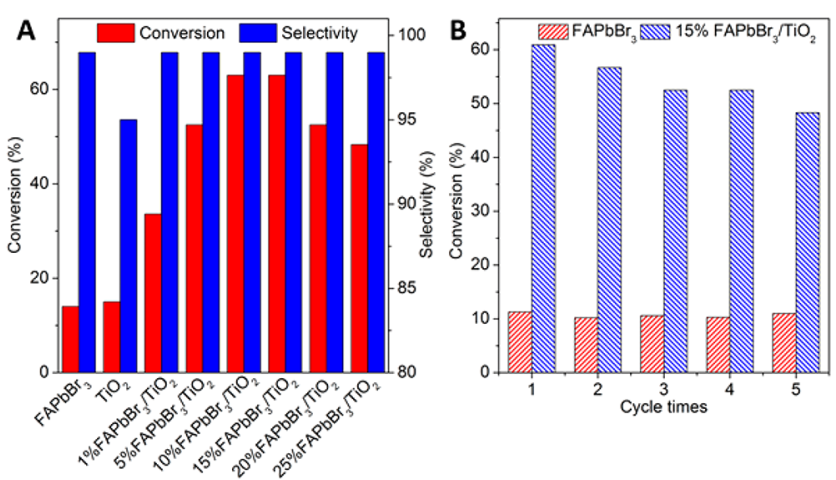

Figure 2. (A) Photocatalytic oxidation of benzyl alcohol over pure $\mathrm{FAPbBr}_{3}, \mathrm{TiO}_{2}$, and a series of $\mathrm{FAPbBr}_{3} / \mathrm{TiO}_{2}$ hybrids. (B) Recycle test for pure $\mathrm{FAPbBr}_{3}$ and $15 \% \mathrm{FAPbBr}_{3} / \mathrm{TiO}_{2}$. Reaction conditions: benzyl alcohol $(0.1 \mathrm{mmol})$, photocatalysts $(0.01 \mathrm{~g})$, solvent of toluene $(2.5 \mathrm{~mL})$ saturated with molecular oxygen, AM1.5G simulated light irradiation, irradiation time $(8 \mathrm{~h})$.

$(10 \mathrm{mg})$ controls both exhibit a conversion rate of roughly $15 \%$ ( $0.1 \mathrm{mmol}$ benzyl alcohol in $2.5 \mathrm{~mL}$ toluene) after $8 \mathrm{~h}$ of illumination. However, their conversion selectivity to benzaldehyde differs from $99 \%$ for pure $\mathrm{FAPbBr}_{3}$ to $95 \%$ for pure $\mathrm{TiO}_{2}$ with benzoic acid as main side product. On the other hand, considering the performance of the $\mathrm{FAPbBr}_{3} / \mathrm{TiO}_{2}$ composite series in Figure 2A, a substantial enhancement is exhibited by the hybrid system, compared to its pure constituents. The addition of only $1 \mathrm{wt} \%$ of $\mathrm{FAPbBr}_{3}$ already leads to a doubling in activity compared to pure $\mathrm{TiO}_{2}$. The highest photocatalytic conversion of benzyl alcohol peaked at $63 \%$ for the 15 wt \% $\mathrm{FAPbBr}_{3} / \mathrm{TiO}_{2}$ composite, totalling a 4-fold enhancement over the pure controls. Further increases in the $\mathrm{FAPbBr}_{3}$ amount exceeding 15 wt \% reduce the conversion rate. This can be attributed to two reasons: (1) The increased quantity of perovskite precursors leads to larger $\mathrm{FAPbBr}_{3}$ nanocrystals and aggregates resulting in longer distances to be traveled by the formed charge carriers and thus reducing the efficiency of charge separation. (2) The increased $\mathrm{TiO}_{2}$ surface coverage by perovskite materials also reduces the exposed surface area of $\mathrm{TiO}_{2}$ to the reagent solution. $\mathrm{TiO}_{2}$ plays an important role in charge separation and it reduces $\mathrm{O}_{2}$ to form the reactive superoxide radical, as described in Scheme 1. As a result of both of these factors, excessive amounts of perovskite will not necessarily lead to further improved photocatalytic performance.

Clearly, combining the two solid-state semiconductors dramatically increases its overall capacity for photocatalytic 
Scheme 1. Experimentally Supported Mechanistic Energy Diagram of Photoinduced Charge Transfer in (A) FAPbBr $_{3}$ and (B) $\mathrm{FAPbBr}_{3} / \mathrm{TiO}_{2}{ }^{26,32}$ (C) Corresponding Schematic of the Proposed Selective Photocatalytic Benzyl Alcohol to Benzaldehyde Oxidation Process over the $\mathrm{FAPbBr}_{3} / \mathrm{TiO}_{2}$ Hybrid
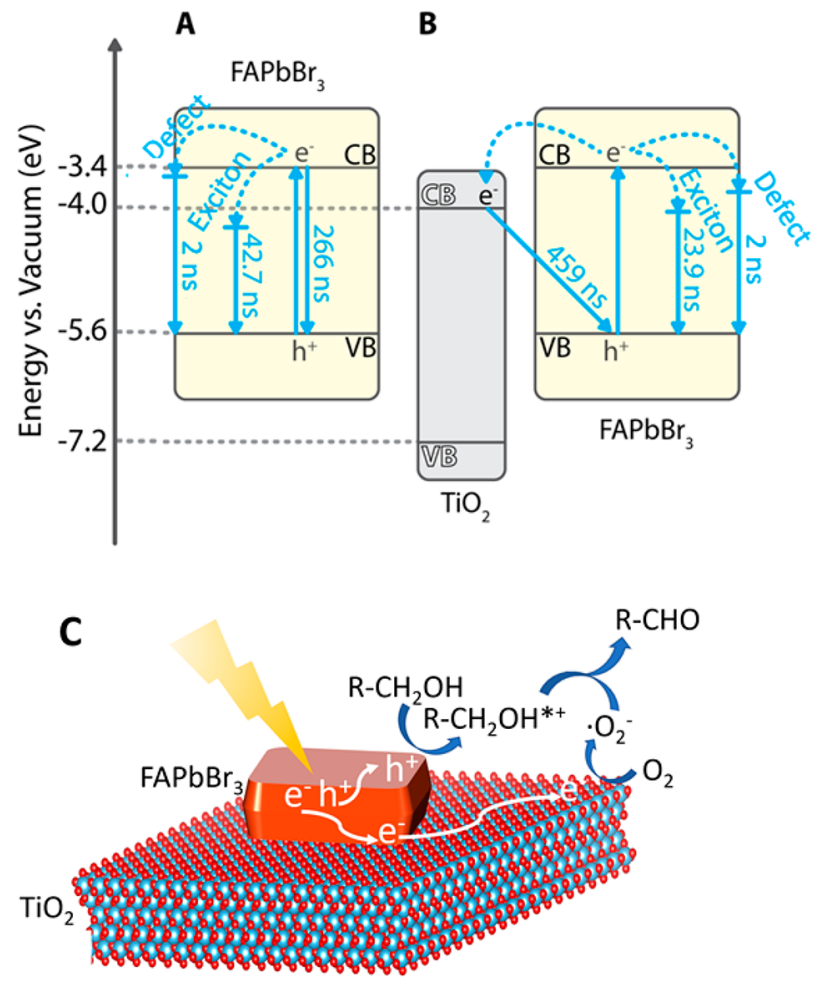

oxidation of benzyl alcohol, without compromising the excellent reaction selectivity (99\% across all composites). However, the potential influence of size effects is yet to be considered. To assess the possible role crystal size might play, nanocrystalline $\mathrm{FAPbBr}_{3}$ was synthesized using an altered synthesis procedure (see the Supporting Information for experimental and characterization details). Additionally, the synergetic role between both materials was evaluated by preparing $\mathrm{FAPbBr}_{3} / \mathrm{SiO}_{2}$ using the same antisolvent method and mechanical mixed $\mathrm{FAPbBr}_{3} / \mathrm{TiO}_{2}-\mathrm{M}$. With these materials, controlling for the morphological parameters such as size and utilizing a mixed media, no discernible benefit was gained; a full summary of the activity results can be found in Table S1. Thus, the enhanced photocatalytic performance exhibited by the $\mathrm{FAPbBr}_{3} / \mathrm{TiO}_{2}$ hybrid systems must ultimately manifest from an intrinsic synergy arising from the interplay between the composite and the interface. ${ }^{18,19}$

The stability of the materials when exposed to repeated reaction cycles is further tested. Figure $2 \mathrm{~B}$ shows the results from both $\mathrm{FAPbBr}_{3}$ and $15 \% \mathrm{FAPbBr}_{3} / \mathrm{TiO}_{2}$ following their reuse as a photocatalyst during five reaction cycles. While no reduction in activity is observed in the pure $\mathrm{FAPbBr}_{3}$ sample, the $\mathrm{FAPbBr}_{3} / \mathrm{TiO}_{2}$ composite slowly decreased in activity. On the basis of additional experiments (Figure S6), we conclude that the more polar reaction product, benzaldehyde, leads to a partial dissolution of the $\mathrm{FAPbBr}_{3}$, an effect that is accelerated by illumination. Therefore, the $\mathrm{FAPbBr}_{3}$ content in the hybrid composite reduces while more benzaldehyde is produced, resulting in a notable effect on the activity of $\mathrm{FAPbBr}_{3} / \mathrm{TiO}_{2}$. The slow dissolution of the perovskite material is currently limiting the long-term stability of the catalysts and causes traces of $\mathrm{Pb}$ to leach into the solution. We remain optimistic that this problem can be resolved in the future by (1) minimizing the contact between the photocatalyst and the more polar reaction products and (2) further developments of lead-free OIHP photocatalysts.

Interestingly, the ability for $\mathrm{FAPbBr}_{3} / \mathrm{TiO}_{2}$ composites to oxidize alcohols with high selectivity is not merely limited to benzyl alcohol. As summarized in Table S2, high selectivity is also realized when performing similar experiments on other aromatic alcohols. Additionally, we further tested other popular wide band gap OIHPs, such as $\mathrm{MAPbBr}_{3}$ and $\mathrm{Cs} \mathrm{PbBr}_{3}$, in the selective photo-oxidation of benzyl alcohol. ${ }^{25}$ Comparable conversions are found on $\mathrm{MAPbBr}_{3} / \mathrm{TiO}_{2}$ and $\mathrm{CsPBr}_{3} / \mathrm{TiO}_{2}$ composites, as summarized in Table S3. These results prove that the described photocatalytic strategy reported here is generic. Similar experiments on material involving iodine, $\mathrm{MAPbI}_{3}$, and $\mathrm{MAPbI}_{3} / \mathrm{TiO}_{2}$, however, were unsuccessful because of photo-oxidation of $\mathrm{I}^{-}$to form $\mathrm{I}_{3}{ }^{-}$, the $\mathrm{Pb}-\mathrm{I}$ bond breakage, and formation $\mathrm{Pb}-\mathrm{O}$ bonds by oxygen intercalated in the perovskite photocatalyst. ${ }^{20,21,26,27}$

Next, we shine light on the photophysical benefit of implementing a hybrid system, over its pure counterparts, by examining their important optical properties. Figure 3A shows

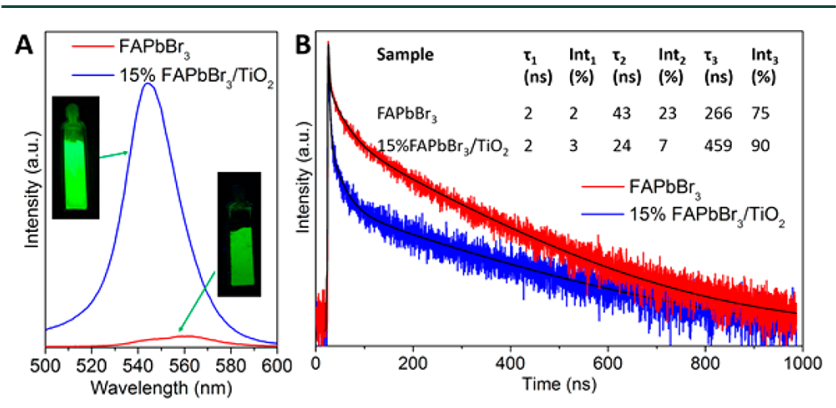

Figure 3. (A) Steady-state PL spectra and (B) PL decay spectra of the prepared $\mathrm{FAPbBr}_{3}$ and $15 \% \mathrm{FAPbBr}_{3} / \mathrm{TiO}_{2}$, including the corresponding multiexponential fitting parameters.

the pronounced effect of $\mathrm{TiO}_{2}$ on the steady-state photoluminescence (PL) spectra of $\mathrm{FAPbBr}_{3}$. Pure $\mathrm{FAPbBr}_{3}$ exhibits the known weak PL emission centered around $560 \mathrm{~nm}$, with a high-energy shoulder near $545 \mathrm{~nm}$ we attribute to the presence of smaller $\mathrm{FAPbBr}_{3}$ nanocrystals (see Figure S2). ${ }^{28,29}$ On the other hand, $15 \% \mathrm{FAPbBr}_{3} / \mathrm{TiO}_{2}$ shows a blue-shifted $\mathrm{PL}$ emission peaking at $545 \mathrm{~nm}$, at the same position as nanocrystalline $\mathrm{FAPbBr}_{3}$ (see Figure S7), assigned to smaller crystallites with a larger band gap (see Figure S8). ${ }^{24,28}$ This is consistent with the DRS and SEM results. More vividly, the PL intensity and $\mathrm{PL}$ quantum yield (PLQY) of $\mathrm{FAPbBr}_{3} / \mathrm{TiO}_{2}$ $(\mathrm{PLQY}=10.4 \%)$ is observed to increase significantly relative to pure $\mathrm{FAPbBr}_{3}$. In the presence of charge-consuming photocatalytic reactions such as the oxidation of benzyl alcohol, the luminescence intensity strongly reduces (Figure S9).

Time-resolved PL analysis is employed to unravel the charge carrier dynamics in the materials' solid state, as shown in Figure 3B. The PL decay kinetics of $\mathrm{FAPbBr}_{3}$ and $15 \% \mathrm{FAPbBr}_{3} / \mathrm{TiO}_{2}$ are agreeably fit with a three-exponential decay function, with their analyzed fit parameters contained in the inset; for completeness, a complete list of parameters used appears in Table S4. Three recombination lifetimes are assigned to distinct processes: trap-assisted $\left(\tau_{1}\right)$, exciton $\left(\tau_{2}\right)$, and free-carrier 
$\left(\tau_{3}\right){ }^{24}$ Note that the difference in charge dynamics between the two decays in Figure 3B resides mainly in the exciton and freecarrier recombination, in that the contribution of the former is reduced from 23\% in $\mathrm{FAPbBr}_{3}$ to $7 \%$ in $\mathrm{FAPbBr}_{3} / \mathrm{TiO}_{2}$ while speeding up from 42.7 to 23.9 ns. Conversely the free-carrier contribution increased from $75 \%$ in $\mathrm{FAPbBr}_{3}$ to $90 \%$ for the $\mathrm{FAPbBr}_{3} / \mathrm{TiO}_{2}$ hybrid system, while $\tau_{3}$ is extended from 266 to $459 \mathrm{~ns}$, respectively. The suppressed exciton recombination and shorter lifetime indicates exciton dissociation at the $\mathrm{FAPbBr}_{3} /$ $\mathrm{TiO}_{2}$ interface, a physical feature used to efficiently extract electrons in solar cell devices. ${ }^{1,30}$ The extraction of electrons to $\mathrm{TiO}_{2}$ leaves holes in the $\mathrm{FAPbBr}_{3}$, increasing free-carrier PL emission, aligning with our previous observations. Moreover, the ratio of free-carrier emission (90\%) in PL decay is in line with a PL intensity drop in toluene after adding benzyl alcohol, indicating the free carriers are involved in the photocatalytic reaction. During the benzyl alcohol photo-oxidation process, the photogenerated charge carriers are separated at the interface between $\mathrm{TiO}_{2}$ and $\mathrm{FAPbBr}_{3}$ and consumed in reactions, thus reducing the $\mathrm{PL}$ emission due to the electron-hole recombination. In addition, the extended free carrier lifetime is favorable for the interfacial transfer of carriers to reactive substrates to achieve a higher photoactivity. ${ }^{31}$ Under light irradiation, this composite forms a long lifetime excitation state to carry out the photoconversion from alcohol to aldehyde. In building a clear picture of how the photocatalytic behavior is so dramatically enhanced for the hybrid system, the different recombination pathways described above are summarized and identified in Scheme 1A,B.

To further support this model, electron spin resonance (ESR) spectroscopy was performed to identify the generated reactive active oxygen species under solar light irradiation with 5,5-dimethyl-1-pyrroline N-oxide (DMPO) is used as the trapping agent (Figure 4A). In the dark, only negligible

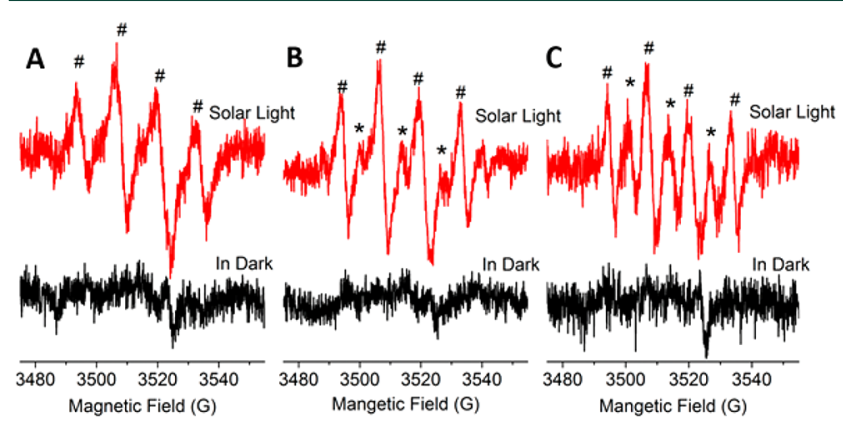

Figure 4. DMPO-trapped (\#) superoxide radical and (*) nitroxidelike radical EPR spectra of (A) $\mathrm{FAPbBr}_{3},(\mathrm{~B}) \mathrm{TiO}_{2}$, and (C) $15 \%$ $\mathrm{FAPbBr}_{3} / \mathrm{TiO}_{2}$ dispersed in toluene.

DMPO- ${ }^{\bullet} \mathrm{O}_{2}{ }^{-}$signals were recorded. ${ }^{33}$ When excited by solar light irradiation, however, the ESR signals of ${ }^{\bullet} \mathrm{O}_{2}{ }^{-}$species in $\mathrm{FAPbBr}_{3}$ increase significantly, indicating that photogenerated electrons in $\mathrm{FAPbBr}_{3}$ reduce $\mathrm{O}_{2}$ to ${ }^{\circ} \mathrm{O}_{2}^{-}$. Besides this ${ }^{\circ} \mathrm{O}_{2}^{-}$ species, the ESR spectra for the $\mathrm{TiO}_{2}$ and $\mathrm{FAPbBr}_{3} / \mathrm{TiO}_{2}$ hybrid show an additional signal coming from the nitroxide radical which is formed by the light-induced cleavage of the $\mathrm{N}-$ $\mathrm{C}$ bond and the ring opening of $\mathrm{DMPO}-{ }^{-} \mathrm{O}_{2}^{-}$adduct. $^{34}$ Because of the $\mathrm{VB}$ alignment, photogenerated electrons in $\mathrm{FAPbBr}_{3}$ can be efficiently funneled into $\mathrm{TiO}_{2}$, as evidenced by our PL results. Therefore, more nitroxide radicals are generated in $\mathrm{FAPbBr}_{3} / \mathrm{TiO}_{2}$, indicating more charge carriers are transferred to $\mathrm{TiO}_{2}$, leading to improved photocatalysis efficiency. In addition, the evacuation of photogenerated electrons from $\mathrm{FAPbBr}_{3}$ to $\mathrm{TiO}_{2}$ leaves densely populated photogenerated holes in $\mathrm{FAPbBr}_{3}$ that are available for oxidation reactions. We summarize the mechanism for the organic transformation over $\mathrm{FAPbBr} 3 / \mathrm{TiO}_{2}$ in Scheme 1: upon solar light illumination, electrons and holes are generated in $\mathrm{FAPbBr}_{3}$ and electrons are injected into $\mathrm{TiO}_{2}$ to reduce the molecular oxygen absorbed on $\mathrm{TiO}_{2}$ into ${ }^{\bullet} \mathrm{O}_{2}{ }^{-}$species, whereas the photogenerated holes remain in $\mathrm{FAPbBr}_{3}$ and oxidize the benzylic alcohol substrates to carbocations. The carbocations react with ${ }^{\bullet} \mathrm{O}_{2}{ }^{-}$species to produce the final product, corresponding to aldehydes.

In summary, the band alignment in the $\mathrm{FAPbBr}_{3} / \mathrm{TiO}_{2}$ composites facilitates the efficient and highly selective photocatalytic oxidization of benzylic alcohols into aldehydes. By funneling the photogenerated electrons from the perovskite into $\mathrm{TiO}_{2}$, an excellent photoactivity and a more than 4-fold enhancement in photocatalytic efficiency are realized. This work sheds light on applications of OIHP materials for broader photocatalytic reactions, not only reduction but also oxidation. We suggest an improved cyclability of such systems can involve an appropriate stabilizing capping agent and conclude that these results ultimately widened the palettte for commercially viable photocatalytic semiconductor systems using OIHPs/ $\mathrm{TiO}_{2}$ hybrid composites.

\section{ASSOCIATED CONTENT}

\section{S Supporting Information}

The Supporting Information is available free of charge on the ACS Publications website at DOI: 10.1021/acsenergylett.8b00131.

Experimental details on materials synthesis and photocatalytic activity measurements, XPS, SEM, diffuse reflectance spectroscopy, and photoluminescence (PDF)

\section{AUTHOR INFORMATION}

\section{Corresponding Authors}

*E-mail: haifeng.yuan@kuleuven.be.

*E-mail: johan.hofkens@kuleuven.be.

*E-mail: maarten.roeffaers@kuleuven.be.

ORCID

Haifeng Yuan: 0000-0001-6652-3670

Dries Jonckheere: 0000-0002-1192-5004

Jinlin Long: 0000-0002-3675-0941

Jelle Hendrix: 0000-0001-5731-1297

Johan Hofkens: 0000-0002-9101-0567

Julian A. Steele: 0000-0001-7982-4413

Maarten B. J. Roeffaers: 0000-0001-6582-6514

Notes

The authors declare no competing financial interest.

\section{ACKNOWLEDGMENTS}

We acknowledge financial support from the Research Foundation-Flanders (FWO, Grant G.0962.13, G0B39.15, ZW15_09 GOH6316N, G.0B49.15, doctoral fellowship to G.S.-F. and postdoctoral fellowships to H.Y., K.P.F.J., E.D. and J.A.S.), KU Leuven Research Fund (C14/15/053), the Flemish government through long term structural funding Methusalem (CASAS2, Meth/15/04), the Hercules foundation (HER/11/ 14), and the European Union (Horizon 2020) Marie Sklodowska-Curie innovation program (Grants 722591 and 
641887 for Ph.D. scholarship) to H.H and C.Y.X.T.. J.L. acknowledges financial support of NSFC (Grant 21773031).

\section{REFERENCES}

(1) Zhao, Y. X.; Zhu, K. Organic-inorganic hybrid lead halide perovskites for optoelectronic and electronic applications. Chem. Soc. Rev. 2016, 45, 655-689.

(2) Lee, M. M.; Teuscher, J.; Miyasaka, T.; Murakami, T. N.; Snaith, H. J. Efficient hybrid solar cells based on meso-superstructured organometal halide perovskites. Science 2012, 338, 643-647.

(3) Kazim, S.; Nazeeruddin, M. K.; Gratzel, M.; Ahmad, S. Perovskite as light harvester: a game changer in photovoltaics. Angew. Chem., Int. Ed. 2014, 53, 2812-2824.

(4) Yang, W. S.; Park, B. W.; Jung, E. H.; Jeon, N. J.; Kim, Y. C.; Lee, D. U.; Shin, S. S.; Seo, J.; Kim, E. K.; Noh, J. H.; et al. Iodide management in formamidinium-lead-halide-based perovskite layers for efficient solar cells. Science 2017, 356, 1376-1379.

(5) Fujishima, A.; Zhang, X. T.; Tryk, D. A. $\mathrm{TiO}_{2}$ photocatalysis and related surface phenomena. Surf. Sci. Rep. 2008, 63, 515-582.

(6) Park, S.; Chang, W. J.; Lee, C. W.; Park, S.; Ahn, H. Y.; Nam, K. T. Photocatalytic hydrogen generation from hydriodic acid using methylammonium lead iodide in dynamic equilibrium with aqueous solution. Nat. Energy 2017, 2, 16185.

(7) Xu, Y. F.; Yang, M. Z.; Chen, B. X.; Wang, X. D.; Chen, H. Y.; Kuang, D. B.; Su, C. Y. A CsPbBr 3 perovskite quantum dot/graphene oxide composite for photocatalytic $\mathrm{CO}_{2}$ Reduction. J. Am. Chem. Soc. 2017, 139, 5660-5663.

(8) Chen, K.; Deng, X. H.; Dodekatos, G.; Tuysuz, H. Photocatalytic polymerization of 3 , 4-Ethylenedioxythiophene over cesium lead iodide perovskite quantum ots. J. Am. Chem. Soc. 2017, 139, 1226712273.

(9) Sheldon, R. A.; Arends, I.; Ten Brink, G. J.; Dijksman, A. Green, catalytic oxidations of alcohols. Acc. Chem. Res. 2002, 35, 774-781.

(10) Sheldon, R. A.; Arends, I.; Dijksman, A. New developments in catalytic alcohol oxidations for fine chemicals synthesis. Catal. Today 2000, 57, 157-166.

(11) Fang, W. H.; Chen, J. S.; Zhang, Q. H.; Deng, W. P.; Wang, Y. Hydrotalcite-supported gold catalyst for the oxidant-free dehydrogenation of benzyl alcohol: studies on support and gold size effects. Chem. - Eur. J. 2011, 17, 1247-1256.

(12) Yamaguchi, K.; Mizuno, N. Supported ruthenium catalyst for the heterogeneous oxidation of alcohols with molecular oxygen. Angew. Chem., Int. Ed. 2002, 41, 4538-4542.

(13) Sheldon, R. A.; Arends, I. Organocatalytic oxidations mediated by nitroxyl radicals. Adv. Synth. Catal. 2004, 346, 1051-1071.

(14) Dijksman, A.; Marino-Gonzalez, A.; Payeras, A. M. I.; Arends, I.; Sheldon, R. A. Efficient and selective aerobic oxidation of alcohols into aldehydes and ketones using ruthenium/TEMPO as the catalytic system. J. Am. Chem. Soc. 2001, 123, 6826-6833.

(15) Dess, D. B.; Martin, J. C. A useful 12-I-5 triacetoxyperiodinane (the Dess-Martin periodinane) for the selective oxidation of primary or secondary alcohols and a variety of related 12-I-5 species. J. Am. Chem. Soc. 1991, 113, 7277-7287.

(16) Mori, K.; Hara, T.; Mizugaki, T.; Ebitani, K.; Kaneda, K. Hydroxyapatite-supported palladium nanoclusters: a highly active heterogeneous catalyst for selective oxidation of alcohols by use of molecular oxygen. J. Am. Chem. Soc. 2004, 126, 10657-10666.

(17) Zhan, B. Z.; White, M. A.; Sham, T. K.; Pincock, J. A.; Doucet, R. J.; Rao, K. V. R.; Robertson, K. N.; Cameron, T. S. Zeolite-confined nano- $\mathrm{RuO}_{2}$ : A green, selective, and efficient catalyst for aerobic alcohol oxidation. J. Am. Chem. Soc. 2003, 125, 2195-2199.

(18) Tan, H. R.; Jain, A.; Voznyy, O.; Lan, X. Z.; de Arquer, F. P. G.; Fan, J. Z.; Quintero-Bermudez, R.; Yuan, M. J.; Zhang, B.; et al. Efficient and stable solution-processed planar perovskite solar cells via contact passivation. Science 2017, 355, 722-726.

(19) Liu, F.; Zhang, Y. H.; Ding, C.; Toyoda, T.; Ogomi, Y.; Ripolles, T. S.; Hayase, S.; Minemoto, T.; Yoshino, K.; Dai, S. Y.; et al. Ultrafast electron injection from photoexcited perovskite $\mathrm{CsPbI}_{3}$ QDs into
$\mathrm{TiO} 2$ nanoparticles with injection efficiency near $99 \%$. J. Phys. Chem. Lett. 2018, 9, 294-297.

(20) Eperon, G. E.; Stranks, S. D.; Menelaou, C.; Johnston, M. B.; Herz, L. M.; Snaith, H. J. Formamidinium lead trihalide: a broadly tunable perovskite for efficient planar heterojunction solar cells. Energy Environ. Sci. 2014, 7, 982-988.

(21) Zhumekenov, A. A.; Saidaminov, M. I.; Haque, M. A.; Alarousu, E.; Sarmah, S. P.; Murali, B.; Dursun, I.; Miao, X. H.; Abdelhady, A. L.; $\mathrm{Wu}, \mathrm{T}$.; et al. Formamidinium lead halide perovskite crystals with unprecedented long carrier dynamics and diffusion length. ACS Energy Lett. 2016, 1, 32-37.

(22) Wang, C. C.; Ying, J. Y. Sol-gel synthesis and hydrothermal processing of anatase and rutile titania nanocrystals. Chem. Mater. 1999, 11, 3113-3120.

(23) Huang, H. W.; Lin, J. J.; Fan, L. Z.; Wang, X. X.; Fu, X. Z.; Long, J. L. Heteroatomic Ni, Sn clusters-grafted anatase $\mathrm{TiO}_{2}$ photocatalysts: structure, electron delocalization, and synergy for solar hydrogen production. J. Phys. Chem. C 2015, 119, 10478-10492.

(24) Zheng, K. B.; Zidek, K.; Abdellah, M.; Messing, M. E.; Al-Marri, M. J.; Pullerits, T. Trap states and their dynamics in organometal halide perovskite nanoparticles and bulk crystals. J. Phys. Chem. C 2016, 120, 3077-3084.

(25) Adinolfi, V.; Peng, W.; Walters, G.; Bakr, O. M.; Sargent, E. H. The Electrical and Optical Properties of Organometal Halide Perovskites Relevant to Optoelectronic Performance. Adv. Mater. 2018, 30, 1700764.

(26) Perumal, A.; Shendre, S.; Li, M. J.; Tay, Y. K. E.; Sharma, V. K.; Chen, S.; Wei, Z. H.; Liu, Q.; Gao, Y.; Buenconsejo, P. J. S.; et al. High brightness formamidinium lead bromide perovskite nanocrystal light emitting devices. Sci. Rep. 2016, 6, 36733.

(27) Yang, Y.; Ri, K.; Mei, A. Y.; Liu, L. F.; Hu, M.; Liu, T. F.; Li, X.; Han, H. W. The size effect of $\mathrm{TiO}_{2}$ nanoparticles on a printable mesoscopic perovskite solar cell. J. Mater. Chem. A 2015, 3, 91039107.

(28) Protesescu, L.; Yakunin, S.; Bodnarchuk, M. I.; Bertolotti, F.; Masciocchi, N.; Guagliardi, A.; Kovalenko, M. V. Monodisperse formamidinium lead bromide nanocrystals with bright and stable green photoluminescence. J. Am. Chem. Soc. 2016, 138, 14202-14205.

(29) Arora, N.; Dar, M. I.; Hezam, M.; Tress, W.; Jacopin, G.; Moehl, T.; Gao, P.; Aldwayyan, A. S.; Deveaud, B.; et al. Photovoltaic and amplified spontaneous emission studies of high-quality formamidinium lead bromide perovskite films. Adv. Funct. Mater. 2016, 26, 28462854.

(30) Gao, P.; Gratzel, M.; Nazeeruddin, M. K. Organohalide lead perovskites for photovoltaic applications. Energy Environ. Sci. 2014, 7, $2448-2463$.

(31) Huang, H. W.; Lin, J. J.; Zhu, G. B.; Weng, Y. X.; Wang, X. X.; $\mathrm{Fu}, \mathrm{X}$. Z.; Long, J. L. A long-lived mononuclear cyclopentadienyl ruthenium complex grafted onto anatase $\mathrm{TiO}_{2}$ for efficient $\mathrm{CO}_{2}$ photoreduction. Angew. Chem., Int. Ed. 2016, 55, 8314-8318.

(32) Mei, A. Y.; Li, X.; Liu, L. F.; Ku, Z. L.; Liu, T. F.; Rong, Y. G.; Xu, M.; Hu, M.; Chen, J. Z.; Yang, Y.; et al. A hole-conductor-free, fully printable mesoscopic perovskite solar cell with high stability. Science 2014, 345, 295-298.

(33) Dvoranova, D.; Barbierikova, Z.; Brezova, V. Radical Intermediates in Photoinduced Reactions on $\mathrm{TiO}_{2}$ (An EPR Spin Trapping Study). Molecules 2014, 19, 17279-17304.

(34) Diaz-Uribe, C. E.; Daza, M. C.; Martinez, F.; Paez-Mozo, E. A.; Guedes, C. L. B.; Di Mauro, E. J. Visible light superoxide radical anion generation by tetra (4-carboxyphenyl) porphyrin/TiO2: EPR characterization. J. Photochem. Photobiol., A 2010, 215, 172-178. 